\title{
Celso Furtado e a formação de economistas
}

Dimas de Oliveira Estevam*

\section{Resumo}

Celso Furtado dedicou grande parte de sua vasta obra à formação profissional do/a economista, destacando a importância do comprometimento profissional desse sujeito para a superação das assimetrias e desigualdades socioeconômicas do País, e ressaltando que a formação do/a economista não pode ser a mesma para todos os países e válida para todas as épocas. Por isso, sua preocupação estava relacionada à dificuldade enfrentada pelos/as estudantes de economia em países subdesenvolvidos, como no caso brasileiro, cujas teorias ensinadas se baseavam em observações feitas mediante a simplificação da realidade, mas que, do ponto de vista estrutural, eram distintas do que era vivenciado pelos/as estudantes. Nesse sentido, o presente artigo aborda o tema da formação de economistas a partir da perspectiva furtadiana. O procedimento metodológico adotado na pesquisa se baseou em fontes bibliográficas de algumas obras do autor, em publicações a seu respeito e em referências complementares. Conclui-se, com base na análise das informações estudadas, que as críticas e os desafios apontados por Furtado sobre a necessidade de economistas comprometidos com os problemas nacionais, além da formação adequada e adaptada à realidade brasileira continuam os mesmos na atualidade.

Palavras-chave: Celso Furtado; Economista; Formação Profissional.

\section{Celso Furtado and the formation of economists}

\begin{abstract}
Celso Furtado dedicated a large part of his vast work to the professional training of the economist, highlighting the importance of this subject's professional commitment to overcoming the socio-economic asymmetries and inequalities of the country, and emphasizing that the training of the economist cannot be the same for all countries and valid for all seasons. Therefore, his concern was related to the difficulty faced by economics students in underdeveloped countries, as in the Brazilian case, whose theories taught were based on observations made by simplifying reality, but which, from a structural point of view, were distinct of what was experienced by students. In this sense, this article addresses the issue of training economists from a furtadian perspective. The methodological procedure adopted in the research was based on bibliographic sources of some of the author's works, on publications about him and on complementary references. It is concluded, based on the analysis of the information studied, that the criticisms and challenges pointed out by Furtado on the need for economists committed to national problems, in addition to adequate training and adapted to the Brazilian reality, remain the same today.
\end{abstract}

Keywords: Celso Furtado; Economist; Professional qualification.

Classificação JEL: A11; A13

\footnotetext{
* Economista e Professor do Curso de Graduação em Economia e do Programa de Pós-graduação em Desenvolvimento Socioeconômico da Universidade do Extremo Sul Catarinense (UNESC), E-mail: doe@unesc.net
} 


\section{Introdução}

Quando abordamos a importância de Celso Furtado para os estudos referentes à realidade socioeconômica brasileira, destaca-se o seu esforço para captar as especificidades de nossa sociedade, afastando-se das análises de estudiosos europeus e norte-americanos ao demonstrar o quanto a nossa realidade é distinta daqueles países. Por esse seu esforço, que lhe é peculiar, podemos colocá-lo entre os principais pensadores do País, também pelo seu grande legado e por suas contribuições para o pensamento social, político e econômico brasileiro.

Entre suas obras, a grande maioria tangencia a formação de economistas em países subdesenvolvidos. Entre elas, destacam-se “A pré-revolução brasileira”, publicada em 1962, e "O mito do desenvolvimento econômico", lançada no ano de 1974, além de outras que também abordam a temática. Para Furtado, a formação dos/as economistas não deveria ser homogênea para todos os países e válida para todas as épocas históricas. Isso porque, quando se analisam comparativamente os países, percebe-se que existem assimetrias entre as economias desenvolvidas e subdesenvolvidas, de maneira que os princípios básicos de economia não são os mesmos de uma nação para a outra, nem mesmo internamente, de região para região (FURTADO, 1962).

Contudo, não se está negando o sentido universal da teoria econômica, sua base comum nem o trabalho dos/as economistas dos demais países, tampouco os mais de dois séculos de desenvolvimento da ciência econômica e suas contribuições para o conhecimento da humanidade. Salienta-se que a dificuldade está em reconhecer o ponto onde termina o caráter universal da ciência econômica e começam os aspectos particulares, definidos pelas questões regionais e pelos sistemas de valor (BRESSER PEREIRA, 1967).

Conforme Celso Furtado (1962, p. 81), "[...] não acreditamos em ciência econômica pura, isto é, independente de um conjunto de princípios de convivência social preestabelecidos, de julgamentos de valor". Embora alguns desses princípios tendam a ser universais, o bem-estar social deve prevalecer sobre o interesse individual. E, também, devido às grandes disparidades nos níveis de desenvolvimento econômico e social, seria errôneo postular para o/a economista uma equívoca ideia de objetividade, similar à contida nas ciências físicas e naturais (FURTADO, 1962).

Sendo assim, consideram-se as preocupações apontadas pelo autor sobre a formação de economistas no País pertinentes à realidade atual. O procedimento metodológico adotado na pesquisa, baseou-se em publicações sobre o autor, além de referências complementares. À vista disso, o presente artigo, além desta parte introdutória, aborda, na segunda seção, os aspectos 
gerais da trajetória dos cursos de economia no Brasil, tratando, por conseguinte, das causas ou motivos da queda na demanda nos cursos de Economia, bem como da formação do/a economista no País. Na seção três, trata da formação de economistas na perspectiva de Celso Furtado. Por fim, na seção quatro, são apresentadas as considerações finais sobre o tema abordado e as referências utilizadas.

\section{Aspectos gerais sobre a trajetória dos cursos de economia no Brasil}

O ensino de economia no Brasil, segundo Castro (1991), embora remonte ao início do século XIX, oficialmente, teve a sua origem na criação do primeiro curso superior em Economia na década de 1930. No entanto, o embrião dos cursos de Economia no País estava vinculado às disciplinas de Economia dos cursos de Direito e Engenharia e, em especial, no ensino técnico comercial. Os cursos técnicos desse período não formavam bacharéis, eram essencialmente práticos, com conhecimentos em contabilidade, direito mercantil e noções de economia política aplicada ao comércio e à indústria. Ressalta-se que os primeiros cursos superiores em Economia foram gestados nessas disciplinas, vinculados a cursos criados durante o século XIX.

É atribuído ao Visconde de Cairu o título de "primeiro economista” brasileiro, segundo Castro (1991), por ser o introdutor da economia política e do liberalismo econômico no País. Os estudos do comércio tiveram seus passos iniciais em seu livro, "Princípios de direito mercantil”, publicado em 1801, em Lisboa. Essa obra foi a primeira publicada em português sobre economia política. Em 1804, Cairu publicou "Princípios de economia política", sendo também atribuída a ele a autoria da abertura dos portos brasileiros em 1808.

Contudo, essa etapa inicial não foi homogênea, podendo ser dividida em três fases: a primeira, vinculada às técnicas comerciais; a segunda, aos cursos de graduação em Direito; por último, aos cursos de graduação em Engenharia. Nela, cada segmento de ensino era dirigido a públicos distintos. Por exemplo: carreiras de nível superior, mais valorizadas, cuja demanda provinha das elites, eram voltadas a advogados e engenheiros; já as funções intermediárias e socialmente menos valorizadas eram ocupadas por aqueles/as com formação em técnicas comerciais (SANSON; NICOLAU, 2007).

A primeira fase da trajetória do curso de Economia no País foi a da criação do curso de Técnicas Comerciais, criado a partir da chegada da família real portuguesa ao Brasil, em 1808, denominado "Aula de Economia Política". Era para ser um curso de nível um pouco acima do que se denomina, atualmente, Ensino Fundamental, com o objetivo de preparar guarda-livros (contadores), comerciários e funcionários públicos ligados ao comércio exterior. O ensino de 
técnicas comerciais era feito em tempo parcial, geralmente à noite (CASTRO, 1991). Essas formas de ensino foram usadas durante o Império e atendiam aos negócios públicos e privados.

A partir de 1827, conforme Sanson e Nicolau (2007), iniciou-se a segunda fase com a criação de faculdades em Olinda e na cidade de São Paulo. Nessas faculdades, a disciplina de Economia Política passou a fazer parte do currículo de Direito, e alguns egressos dessas escolas passaram a ser denominados "Advogados-Economistas", influenciando, por um longo período, o pensamento econômico brasileiro. Em 1863, iniciou-se a terceira fase da trajetória do ensino de economia, com a criação dos cursos de Engenharia, tendo as disciplinas de Economia na grade curricular. Os formandos desses cursos eram conhecidos como "EngenheirosEconomistas", que também passaram a ter influência no pensamento econômico do País. Nesses cursos, as disciplinas de Economia eram voltadas a aspectos instrumentais no campo das finanças e da organização industrial. Esses dois cursos (Direito e Engenharia) formaram os primeiros economistas brasileiros.

A primeira faculdade de Economia no País foi criada em 1919, sob o título Faculdade de Ciências Políticas e Econômicas do Rio de Janeiro. Entretanto, sem o reconhecimento oficial, que aconteceu apenas em 1926 (Decreto n ${ }^{\circ}$ 17.329), quando os/as egressos/as passaram a receber o título de "graduado/a em Ciências Econômicas e Comerciais". Ressalta-se que o/a formado/a não recebia o título de bacharel, o qual era concedido somente aos concluintes dos cursos de Medicina, Engenharia e Direito (CASTRO, 1991). Todavia, o primeiro curso de Ciências Econômicas integrado a uma estrutura universitária surgiu em 1946, com a criação do curso de Economia na Faculdade de Ciências Econômicas da Universidade do Brasil, posteriormente denominada Faculdade de Economia e Administração, o atual Instituto de Economia da Universidade Federal do Rio de Janeiro (UFRJ). Na altura de sua criação, o currículo adotado na UFRJ passou a ser padrão no País.

A profissão de Economista foi regulamentada pela Lei nํㅡ 1.411, de 13 de agosto de 1951 (BRASIL, 1951), a qual designa o exercício profissional aos bacharéis em Ciências Econômicas diplomados no Brasil. A partir da promulgação dessa lei, o dia 13 de agosto passou a ser reconhecido e comemorado como o "Dia do Economista" no País.

O primeiro currículo mínimo de economia, criado pelo Decreto no 20.158 , de 30 de junho de 1931, era composto, em grande parte, por disciplinas voltadas às áreas jurídica, financeira, contábil e administrativa, integradas por matérias de economia política, geografia econômica, história econômica e fontes da riqueza nacional, totalizando dezessete disciplinas. Embora o currículo tivesse um peso elevado de disciplinas das áreas jurídicas, de administração 
e de contabilidade, havia, contudo, um grande número de disciplinas de economia, as quais continuam sendo obrigatórias na atualidade (CASTRO, 1991).

Cabe ressaltar, nesse período, que o ensino de ciências econômicas não se desvinculou totalmente de suas origens e das profissões afins. Era comum a predominância de técnicos comerciais nas primeiras turmas, devido à origem de grande parte dos professores e, também, de bacharéis em Direito e Engenharia. A partir de 1962, concretizou-se a separação entre economia, contabilidade e atuária, mediante pareceres e resoluções específicos do Conselho Federal de Educação (CFE), já na vigência da Lei de Diretrizes e Bases (LDB). Entre as características relevantes do currículo mínimo de 1962, está a separação do ciclo básico e do ciclo de formação profissional e a divisão entre as matérias de economia e as acessórias (CASTRO, 1991). A duração do curso foi fixada em quatro anos, e a carga horária mínima foi regulamentada, em 1965, pelo Ministério da Educação (SANSON; NICOLAU, 2007).

A crítica feita por Celso Furtado a respeito dessas faculdades era sobre como os seus conteúdos chegavam ao País. Eram importados da Europa, penetravam as faculdades daqui e transformavam-se em um "corpo de doutrina", sendo aceitos independentemente de contraponto com a realidade do País. Dessa maneira, a realidade se distanciava do mundo ideal da doutrina, supondo-se o início daquilo que o autor denominou "patologia social". Desse modo, passava-se diretamente de uma interpretação idealista da realidade para uma política, excluindo qualquer possibilidade de crítica à doutrina em confronto com a realidade (FURTADO, 1962).

Esse currículo esteve em vigência até 1984, quando o CFE publicou a Resolução no 11/84, aprovando o novo currículo de Economia (ANGE, 2010). As mudanças contemplaram os debates sobre as características que deveriam ter o curso de Economia no Brasil. As novas Diretrizes Curriculares foram aprovadas pelo CNE por meio da Resolução no 04/2007 (BRASIL, 2007b), que manteve a estrutura básica de 1984. A estrutura atual dos cursos de Economia foi instituída pelas Diretrizes Curriculares Nacionais, em nível de bacharelado, a ser observada pelas Instituições de Educação Superior (IES) em sua estrutura curricular. A Resolução no 02/2007 do CNE (BRASIL, 2007a) definiu a carga horária mínima dos cursos em 3.000 horas-aula, e a duração mínima de quatro anos para a integralização do currículo.

No subitem a seguir, apresentam-se algumas causas ou motivos da queda na demanda nos cursos de Economia do País. 


\subsection{Causas ou motivos da queda na demanda nos cursos de Economia}

No Brasil, o número de estudantes matriculados/as nos cursos de Ciências Econômicas tem apresentado tendência de queda. Conforme dados do Instituto Nacional de Estudos e Pesquisas Educacionais Anísio Teixeira - INEP (BRASIL, 2019), apresentados na Tabela 1, entre 1997 a 2018, o número de estudantes de Ciências Econômicas apresentou redução de 9,9\% nas matrículas, ou seja, de 65.795 caiu para 53.449 alunos/as no período. Em 1997, os/as estudantes de Ciências Econômicas representavam 3,39\% do total de estudantes matriculados no ensino superior no País. Já em 2010, representavam 0,93\% do total das matrículas. Conforme os dados da Tabela 1, em 2018, havia 250 Instituições de Ensino Superior (IES) que ofertavam 250 cursos de Economia no Brasil, com 53.449 alunos/as matriculados/as. Contudo, a evasão no curso se apresentou elevada em 2018, visto que apenas 12,2\% (6.519) dos/as estudantes o concluíram.

Tabela 1: Dados gerais dos cursos de economia presenciais e a distância no Brasil em 2018

\begin{tabular}{l|c|c|c}
\hline Categoria Administrativa & Cursos & Matrícula Total & Concluinte Total \\
\hline Pública Federal & 71 & 21.466 & 2.164 \\
\hline Pública Estadual & 39 & 10.365 & 1.106 \\
\hline Pública Municipal & 3 & 294 & 662 \\
\hline Privada com fins lucrativos & 65 & 9.858 & 766 \\
\hline Privada sem fins lucrativos & 69 & 11.308 & 1.783 \\
\hline Especial & 3 & 158 & 39 \\
\hline Total & $\mathbf{2 5 0}$ & $\mathbf{5 3 . 4 4 9}$ & $\mathbf{6 . 5 1 9}$ \\
\hline
\end{tabular}

Fonte: Inep (BRASIL, 2019) - Censo da Educação Superior (Adaptado).

Além das questões apontadas por Furtado sobre os problemas na formação profissional do/a economista, mais à frente são apresentados os desafios na formação profissional na perspectiva do autor. Outros autores, nacionais e internacionais, têm apontado as dificuldades, como as evidenciadas por Fanaya (2007), para justificar a queda na demanda, entre as quais estão as funções assumidas por profissionais de outras áreas de formação, os quais têm sua formação complementada em cursos de especialização, em áreas de atuação dos/as economistas, sendo grande parte composta por engenheiros, administradores, advogados, contadores, entre outros. Além disso, o autor aponta a omissão dos/as próprios/as economistas quando são instados/as a identificarem-se profissionalmente. Na maioria das vezes, relacionam a sua especialização (doutorado, mestrado ou especialização) à profissão.

Para o autor supracitado, há, com isso, um processo de desintegração da profissão, levando-a a ser considerada sinônimo de ocupações ou de cargos, tais como consultor, analista, conferencista, pesquisador, executivo, diretor, entre outras designações. As possibilidades de 
substituição da denominação são inúmeras e variadas, verificando-se também em carreiras tradicionais, como funcionário público, bancário, professor, militar, auditor, entre outras. Diante disso, a expressão "economista" é relegada a segundo plano (FANAYA, 2007).

Outros motivos para o declínio da profissão são apontados por Pinto e Oliveira (2010) ao explicarem a diminuição da demanda de estudantes no Brasil, dentre os quais está a linguagem utilizada pelos/as próprios/as economistas, que é pouco compreensível à opinião pública. As pessoas não familiarizadas com os jargões econômicos ("economês") têm dificuldade para entender os temas abordados por eles/as. Para complicar a compreensão do público em geral, os/as economistas acreditam demasiadamente em modelos matemáticos para dar conta das relações sociais e econômicas, como se elas fossem previsivelmente exatas e como se a vida se reduzisse a números, taxas e índices.

Mais causas das dificuldades na formação do economista no País foram ressaltadas por Mário Henrique Simonsen, de corrente distinta da de Celso Furtado. Para Simonsen (1966), os economistas saem das faculdades com certas deficiências na formação; de modo geral, o autor pontua as mais frequentes: falta de conhecimento básico em matemática e estatística; dificuldade de raciocínio lógico e incompreensão do método científico; conhecimento desintegrado da análise econômica (muitas faculdades ensinam ideias vagas sobre economia, como consequência, os/as economistas ficam com dificuldades para utilizar conceitos em problemas práticos); falta de informação institucional (boa parte dos egressos em Economia saem das escolas sem conhecer o funcionamento dos instrumentos de política econômica adotados no País).

Outros motivos para a demanda decrescente do curso, segundo Pinto e Oliveira (2010), estão na pouca familiaridade em esclarecer o campo de atuação do/a profissional economista. Muitas vezes, não é explicado com clareza sobre referido campo de atuação, que pode ser em espaços de atividades públicas e privadas, dada a abrangência de conhecimentos sólidos que o curso fornece, não se limitando a dados técnicos e matemáticos, mas abrangendo toda uma discussão dos processos históricos, sociais e políticos do País.

Além dos motivos apontados acima, Assis e Doria (2011) atribuem esse declínio à subjetividade humana, que ficou reduzida a números e a fórmulas matemáticas, isso porque a matemática se tornou um meio para estabelecer autoridade, além de possibilitar a seus formuladores uma superioridade política. Espantoso é o silêncio de grande parte da comunidade acadêmica sobre a questão. Contudo, o maior perigo das ciências econômicas não está na resistência à utilização de cálculos, mas no abuso do que se pode fazer com os números. 
Autores internacionais, como Amartya Sen e Karl Polanyi, também dedicaram parte de suas obras para elucidar os motivos de a economia ter se afastado do mundo real, transformando-se em uma ciência abstrata. Sen (1999) tem recorrido às ideias de Adam Smith para compreender as causas do empobrecimento do ensino de ciências econômicas na atualidade. Para o autor, em Smith, a economia tem duas origens, ambas relacionadas com a política, embora diferentes - por um lado, a "ética", e, por outro, a "engenharia". Na abordagem da "engenharia", foi caracterizada pelo fato de focar em questões logísticas, de números e cálculos e não nos fins fundamentais de promover "o bem-estar". Na questão ética, a economia afastou-se de seu compromisso com o ético (mundo da política).

A primeira origem (ética), conforme Sen (1999), remonta a Aristóteles, tendo como expoentes modernos Adam Smith, John Stuart Mill, Karl Marx, entre outros. A outra centra-se na descrição mecânica das relações sociais, fundadas nos aspectos logísticos. Essa linha tem como principais representantes William Petty, François Quesnay, David Ricardo, Léon Walras, entre outros pensadores. Nessa perspectiva, o comportamento humano é baseado em motivos simples e facilmente caracterizáveis. Essa abordagem tornou-se dominante na economia durante o século $\mathrm{XX}$, consequentemente, as análises econômicas da ética foram sendo enfraquecidas no campo da economia.

A economia deve se dedicar às questões coletivas, por isso é um ramo da política (ética). Para Sen (1999), esse tema tem importância no estudo da economia. Por um lado, tem-se as questões da motivação humana, isto é, a questão ética: “como devemos viver?”. Por outro, a abordagem da "engenharia" é caracterizada por preocupar-se com as questões logísticas, focadas em encontrar meios para atingir determinados fins. Segundo Sen (1999), o distanciamento dessas duas origens empobreceu a economia moderna e contribuiu para um "caráter não ético" da economia, mesmo ela devendo grande parte de sua trajetória à filosofia moral.

Pode-se afirmar que dimensão ética, na economia moderna, foi sendo reduzida em sua trajetória, não só perdendo espaço e relevância, mas também causando problemas práticos no estudo econômico. Como no caso da "economia positiva", que não apenas se esquivou da análise econômica normativa, como também deixou de lado uma variedade de considerações éticas complexas as quais afetam o comportamento humano real e que, do ponto de vista dos/as economistas que estudam esse comportamento, são primordialmente fatos e não juízos normativos (SEN, 1999).

Assim, a "economia positiva", corrente dominante no pensamento econômico, preconiza que a economia é uma ciência positiva. Apesar desses economistas reconhecerem a 
existência de uma economia normativa, consideram que ela ainda não atingiu a maturidade do pensamento positivo devido ao seu apego às considerações morais (éticas). Por isso a dificuldade de diálogo entre as correntes e o distanciamento entre ética e logística (SEN, 1999).

Esse distanciamento apontado por Amartya Sem, também já havia sido verificado por Karl Polanyi (1980) ao observar a desconexão entre a economia e as demais ciências. O autor (1980) fez suas ponderações sobre a crença de alguns economistas quanto à existência de "leis naturais" na economia. Como exemplo, a "lei" da oferta e procura, apresentada como se o mercado tivesse suas "leis" naturais próprias e que não fosse constituído de relações humanas (política, social, cultural e moral). Dessa maneira, coloca-se a realidade econômica sob a autoridade da própria natureza, fazendo-nos acreditar que os mercados são instituições naturais regidas espontaneamente e que, por isso, devem ficar em paz. Nesse sentido, a sociedade deve se "sujeitar" às leis não humanas, às leis da natureza (POLANYI, 1980).

Ainda, com base na análise de Polanyi (1980), seu legado continua atual, principalmente sobre a sua crítica à teoria econômica mainstream e às instituições de uma sociedade cuja economia é regulada por um sistema globalizado de mercados. Segundo o autor, essa forma de encarar a economia engendrou um economicismo arrogante que distanciou a reflexão econômica não apenas das considerações éticas, mas também da sociologia, antropologia, geografia, história, psicologia. O pretenso universalismo do cálculo econômico levou ao monopólio semântico do termo economia, encobrindo a existência de seus outros sentidos e significados.

A partir dessa interpretação, conforme Polanyi (1980), a escassez passou a ser o postulado da insuficiência das coisas materiais (a crença de que não há o suficiente para todos/as). A associação da economia com a "escassez" parece óbvia, pois está presente na própria terminologia "economizar" (poupar) e em "econômico" quando vinculado a barato. Por meio dessa associação, a condição humana parece que leva a uma "tragédia predestinada", ou seja, somos prisioneiros do trabalho, da perpétua disparidade do paradoxo dos desejos infinitos e dos meios insuficientes para alcançá-los.

Polanyi (1980) demonstrou a não existência da escassez em outras sociedades, mesmo vivendo em condições materiais limitadas. O que diferencia a sociedade atual é que ao invés de a economia estar embutida nas relações sociais, são as relações sociais que estão embutidas no sistema econômico. A tese defendida pelo autor é de que a percepção de um mercado que se autorregula era uma ideia utópica. A economia definida como a ciência da alocação eficiente de recursos escassos, visando à maximização da utilidade individual e ao mercado como lugar 
de encontro entre a oferta e a demanda, onde se formam os "preços de equilíbrio", isso era uma interpretação idealista (POLANYI, 1980).

Por isso, as ponderações de Polanyi (1980) sobre os equívocos do mainstream econômico se constituíram em um suporte importante para enfrentar os grandes desafios para a formação de futuros/as economistas, proporcionando caminhos alternativos que corroboram a construção de pensamentos alternativos, como os propostos por Furtado, sem cair nos modismos. A lógica utilitarista do indivíduo interessado em si próprio tem se demonstrado incapaz de enfrentar os desafios atuais, como a destruição da natureza e da vida, a concentração da riqueza e demais consequências. Quando se busca a maximização de nossos interesses próprios, os resultados tendem a ser desastrosos para todos/as (POLANYI, 1980).

No "Mito do Desenvolvimento", Furtado (1974), reforça as questões apontadas por Polanyi, particularmente para tratar sobre a formação do/a economista, visto que dentro desse arcabouço teórico seu campo de observação fica limitado a processos parciais. A formação fica centrada em análises descontextualizadas, tornando a formação abstrata e com pouco nexo com a realidade. Com isso, o/a profissional, ao confrontar-se com o mundo real, sente-se frustrado/a (FURTADO, 1961).

Diante do que foi apresentado acima, existem muitas razões e motivos para explicar ou justificar a queda na demanda ou mesmo a falta de interesse pelos cursos de Economia. Celso Furtado (1961) foi um dos pioneiros a tratar especificamente a respeito do problema, inicialmente apontando a maneira como os conteúdos chegavam às faculdades brasileiras. $\mathrm{Ou}$ seja, eram importados de países desenvolvidos, penetravam nas faculdades e transformavamse em um "corpo de doutrina", aceitos independentemente de fazerem o contraponto com a nossa realidade. O mundo concreto se distanciava do mundo ideal da doutrina, formando aquilo que o autor denominou "patologia social". Ou seja, passava-se diretamente de uma interpretação idealista da realidade para a política, excluindo qualquer possibilidade de crítica à doutrina em confronto com a realidade (FURTADO, 1962). Os problemas detectados por Furtado, na década de 1960, ainda podem se relacionar com o que acontece atualmente.

Contudo, ressalta-se que no campo da economia, apesar da lógica instrumental florescer de muitas fontes, dispõe-se ao menos conceitualmente de sólidos marcos teóricos. No entanto, são inúmeros economistas dissidentes do mainstream de diferentes ramificações, como Celso Furtado, assunto tratado na próxima seção. 


\section{A formação do/a economista na perspectiva de Celso Furtado}

Celso Furtado já tinha percebido em seus estudos iniciais que o/a estudante de economia enfrentava grandes dificuldades em seu aprendizado. Isso se devia, segundo Furtado (1961), às teorias ensinadas nas universidades estarem distantes da realidade do País. O ensino estava sendo feito com simplificações, muitas vezes ditadas pela conveniência do uso de técnicas de análises importadas e não adaptadas à nossa realidade. Para o autor, não se deve esquecer de que quando se analisa o mundo real, adota-se uma técnica de análise preexistente à escolha do objeto analisado. Com isso, afasta-se da realidade, como se pudesse avançar apenas pelos caminhos abertos pela análise do cálculo diferencial, da estatística e da econometria (FURTADO, 1961).

Esse distanciamento do mundo concreto foi enfatizado na obra lançada pelo autor em 1964, intitulada "Dialética do desenvolvimento", que trata da missão e da responsabilidade dos intelectuais na sociedade. Ele não considerava a existência de uma moral dos intelectuais por cima de quaisquer escalas de valores, as quais estavam/estão necessariamente inseridas em algum contexto social. Porém, não se pode desconhecer suas responsabilidades sociais. Uma sociedade não somente pode, como deve sobrepor-se às condicionantes sociais mais imediatas do comportamento individual. Isso lhe faculta mover-se em um plano de racionalidade mais elevado e outorga-lhe uma responsabilidade toda especial: a da inteligência (FURTADO, 1964).

A obra "A pré-revolução brasileira" (1962) é direcionada à juventude universitária. Nela, o autor manifesta a sua preocupação com a formação do/a economista. A sugestão é dedicar-se à causa nacional e romper com o passado oligárquico, pois o País havia alcançado um nível de maturidade e tinha condições de tomar decisões sobre sua vida econômica, mas ainda era caracterizado por um nível de renda per capita típico de país subdesenvolvido. Embora tivéssemos conquistado maior autonomia nas decisões, ainda havia grande incerteza sobre o futuro, agravada pelo fato de interpretar-se a realidade econômica com um aparato conceitual inadequado (FURTADO, 1962).

Nesse período, o Estado brasileiro ainda se encontrava desaparelhado para o exercício de suas novas funções como principal instrumento do desenvolvimento. Furtado aponta o desmedido custo social do desenvolvimento que vinha se realizando, incapaz de mudar as condições de vida de três quartos da população. Por isso, o Estado necessitaria ser administrativamente reestruturado e haveria necessidade de um maior entrosamento entre 
especialistas em ciências políticas, administrativas e econômicas, condição indispensável ao êxito da política de desenvolvimento e da reconstrução do País (FURTADO, 1962).

Nessa mesma obra referenciada acima, o autor chama a atenção para as assimetrias existentes entre economias desenvolvidas e subdesenvolvidas e para o fato de que os princípios básicos não são os mesmos de uma para a outra (as soluções não podem ser pré-fabricadas). Por isso, a formação do/a economista era considerada abstrata, e a dificuldade enfrentada pelo/a estudante de economia, em um país subdesenvolvido, era que as teorias ensinadas se baseavam em observações simplificadas do mundo real, distintas da realidade vivida.

Segundo Furtado (1961), o/a economista, ao confrontar-se com o mundo real, sente-se frustrado ao perceber que é mais importante compreender as limitações de natureza administrativa e fiscal em uma empresa que conhecer os sutis caprichos da posição de equilíbrio de uma firma teórica. Para fazer um bom estudo de mercado, é necessário saber trabalhar com a imaginação, base de dados e informações indiretas, visto que esses aspectos são mais importantes do que as refinadas técnicas de análise. Para Furtado, se o/a economista optar por trabalhar no setor público, a desorientação poderá ser ainda maior; nesse caso, descobrirá que quase tudo do que aprendeu é quase totalmente inútil e o que é útil deixou de aprender. Esses aspectos são, para o autor (1961), a chave para entender o problema da formação do/a economista no País.

Contudo, Furtado (1961) admite que não é tarefa fácil dar esse passo decisivo do campo das doutrinas (terreno da lógica) para o campo das teorias científicas (eficácia explicativa), em um país como o Brasil. Segundo o autor, ao falar de doutrina, está se referindo a um protótipo ideal, ao passo que a teoria científica diz respeito a uma determinada realidade. O que tem ocorrido no ensino de economia é que uma teoria formulada para explicar uma dada realidade, com limites no tempo e no espaço, é transformada em doutrina com caráter universal. Furtado cita como exemplo que uma teoria desenvolvida para explicar a balança de pagamentos de um país, quando universalizada, transforma-se em doutrina, a qual pode servir para justificar determinadas políticas, mas não para explicar indiscriminadamente a realidade de qualquer país.

A ciência econômica exerce forte influência devido à aparente exatidão dos métodos utilizados. Conforme Furtado (1974), de modo geral, os/as economistas tratam os fenômenos de forma quantitativa, ao menos na aparência, os quais são isolados e analisados em seu contexto. Ao serem identificadas as relações estáveis entre fenômenos, abre o caminho à verificação e à previsão, que são as características essenciais do conhecimento científico. Muitos/as economistas têm se empenhado em traduzir a realidade econômica em linguagem de 
análise matemática. Portanto, o progresso da economia se faz no sentido de uma aplicação crescente do método científico, o qual tem o seu paradigma na ciência física (FURTADO, 1974).

Ocorre que o objeto de estudo da economia não é uma natureza estática a si mesma, ela é totalmente exterior ao ser humano, como são os objetos estudados nas ciências naturais. De acordo com Furtado (1974), para que o preço do arroz fosse algo objetivo, deveria ser, como se ensina nos manuais de economia, o resultante da interação entre a procura e a oferta, dotada de existência objetiva. Seria como se a oferta de arroz dependesse somente da precipitação pluviométrica, e a sua procura dependesse das necessidades fisiológicas de um determinado grupo de pessoas. Contudo, a oferta de arroz é condicionada por uma série de fatores sociais, os quais vão desde o crédito para financiar estoques até o uso de pressões para importar ou exportar o produto, o controle dos meios de transporte, o grau de monopólio dos mercados, entre outros fatores (FURTADO, 1974). Por isso, para o autor (1974, p. 115),

\footnotetext{
Nem o mais ingênuo jovem economista doutrinado em Chicago acredita hoje em dia no mito da "soberania" do consumidor como princípio ordenador da vida econômica. Ademais, admitida a hipótese da "soberania" do consumidor, em que basear a introdução do postulado da homogeneidade, isto é, como somar as preferências de um milionário com as de um pobre que passa fome?
}

Para o autor, os/as economistas, via de regra, pensam como tal e levam a que outras categorias sociais assimilem essa visão, sem suspeita de que se possa estar crendo em uma falácia.

Toda decisão econômica é parte de um conjunto de decisões com importantes projeções e repercussões no tempo. As decisões encontram sua coerência última em um projeto que introduz um sentido unificador na ação do agente. Isolar uma decisão do conjunto dotado de sentido, que é o projeto do agente, considerá-la fora do tempo e, em seguida, adicioná-la a decisões pertencentes a outros projetos como se ela se tratasse de elementos homogêneos “"[...] é algo fundamentalmente distinto do que em ciência natural se considera como legítima aplicação do método analítico" (FURTADO, 1974, p. 114).

Essa conclusão do autor se impõe a respeito da análise macroeconômica, a qual pretende explicar o comportamento de um sistema econômico nacional. Nesse caso, as definições dos conceitos e das categorias básicas da análise estão diretamente influenciadas pela visão inicial que tem o/a economista do projeto implícito na vida social, o qual se apresenta como um processo ou como um conjunto de fenômenos em interação e adquire sentido mediante a ótica dos agentes que controlam os centros de decisões, ou seja, exercem poder. Da mesma maneira, a concentração do poder econômico (grandes empresas) e da manipulação da informação 
(grandes redes de comunicação) facilita a identificação de estruturas colaterais de poder. E em torno das decisões emanadas dos centros principais de poder se ordena o amplo processo da vida social.

Furtado, nesse contexto, trata ainda do empobrecimento cultural e faz uma crítica epistemológica da "economia positiva", sobretudo ao que chamou de "vaca sagrada dos economistas", o Produto Interno Bruto (PIB), por conter definições e arranjos arbitrários. Entre eles está a exclusão, no cálculo do PIB, dos impactos da destruição dos recursos naturais e seus custos para a coletividade, como a poluição do ar e das águas. Os/as economistas delimitam um campo de trabalho restrito à observação de processos parciais, ignorando que esses processos provocam crescentes modificações no mundo físico (FURTADO, 1974).

Para Furtado (1974, p. 117), o PIB é um

[...] conceito ambíguo, amálgama considerável de definições mais ou menos arbitrárias, transformou-se em algo tão real para o homem da rua como o foi o mistério da Santíssima Trindade para os camponeses da Idade Média na Europa. Mais ambíguo ainda é o conceito de taxa de crescimento do PIB.

Conforme o autor, para elevar a taxa de crescimento do PIB, deve-se aumentar o consumo supérfluo, em termos relativos, bastando concentrar a renda. Dito de outra maneira, quanto mais se concentra a renda, mais privilégios se criam, maior é o consumo supérfluo, maior será a taxa de crescimento do PIB. "Desta forma a contabilidade nacional pode transformar-se num labirinto de espelhos, no qual um hábil ilusionista pode obter os efeitos mais deslumbrantes" (FURTADO, 1974, p. 118). Para o autor, o avanço das ciências econômicas depende da capacidade de autocrítica, por isso não é de surpreender que as ciências se degradem quando declinam do exercício da autocrítica.

Outra crítica referente à formação do/a economista diz respeito à sua inaptidão para captar os problemas do desenvolvimento, devido à sua formação ou à sua maneira de pensar, estar presa à ideia de equilíbrio geral e de "automatismos autocorretores". Para Furtado (1962), essa forma de captar a realidade decorre da tendência entre os/as economistas de pensar o mundo em função de modelos e de constructos abstratos, o que supõe certo padrão e regularidade.

A maneira de ensinar uma ciência deveria partir de seus quadros conceituais como sistemas de hipóteses, cuja eficácia explicativa deveria ser testada com respeito a uma determinada realidade. Segundo Furtado (1962), isso raramente é feito, no ensino de economia, quando muito se demonstra a consistência lógica interna do sistema de hipóteses, partindo de um conjunto de definições. Dificilmente se aborda o problema de sua eficácia explicativa com 
respeito a uma determinada realidade empírica. Ou seja, "[...] raramente se passa do campo da doutrina para o da teoria científica" (FURTADO, 1962, p. 96).

Devido às dificuldades na aplicabilidade de boa parte das teorias econômicas nas estruturas subdesenvolvidas, Furtado (1961) considera que, na formação do/a economista, deveria ser priorizado o domínio das técnicas que capacitem a observação de forma sistemática à realidade econômica, pois saber observar o mundo real e saber retirar da realidade os meios disponíveis e os elementos necessários à sua representação em termos econômicos é mais importante do que um refinado conhecimento dos mais sutis modelos escolásticos (FURTADO, 1961).

Em razão do caráter histórico dos fenômenos econômicos, deve-se levar em conta que a validez de uma teoria é muito mais limitada em economia do que em outras áreas do conhecimento. Para Furtado (1961), em ciência, explicar significa estar munido para prever; já em economia, explica-se dez para poder prever um, e o que se logra prever é sempre o mais geral, ou melhor, aquilo que é comum a uma multiplicidade de fenômenos, consequentemente, tem um caráter histórico limitado. Ou seja, aquilo que é mais específico de uma determinada realidade é o que mais dificilmente pode ser previsto. O/a economista com uma base sólida do método científico, em geral, perceberá que a imaginação é um instrumento poderoso de trabalho. Na medida em que venha a pensar por conta própria, com independência, reconquistará a autoconfiança e perderá a perplexidade (FURTADO, 1961).

Outro ponto destacado por Furtado (1961) e que exige análise cuidadosa diz respeito à necessidade de que se tenha uma política de desenvolvimento em consonância com as características continentais do País, e ao reconhecimento de que o desenvolvimento não pode continuar a processar-se à custa das desigualdades sociais crescentes. Essa questão deve ser objeto de debates e de estudos sistemáticos entre os/as economistas. Para obter êxitos, é preciso, então, trabalhar em conjunto com especialistas de outras áreas das ciências sociais, principalmente os estudiosos da ciência política e da administração (FURTADO, 1962).

Os temas referidos pelo autor para reflexão são relevantes para indicar a importância da discussão sobre problemas econômicos brasileiros. As desigualdades sociais e as disparidades regionais, entre ritmos de crescimento de sistemas econômicos, também são matéria de competência de economistas (FURTADO, 1961). Os/as economistas que têm essa preocupação poderão contribuir para que se forme uma consciência mais objetiva da realidade e para que novos elementos de racionalidade sejam introduzidos no debate dos problemas de política econômica. Para Furtado (1962), pensar com clareza constitui um dever de todos/as aqueles/as que têm em suas mãos uma parcela de responsabilidade. 
Nos anos noventa, Furtado lançou a obra "Brasil: a construção interrompida" (1992), na qual aponta os equívocos e os fracassos das políticas econômicas e sociais, estruturadas a partir do Consenso de Washington e do Banco Mundial. Em "novos desafios", pequeno texto publicado em 1991, suas reflexões para retomar essa construção interrompida sugerem mudança de rumo da civilização, a qual exige o abandono de ilusões e exorcismo dos fantasmas de uma modernidade que nos condena a um mimetismo cultural esterilizante (FURTADO, 1991). De certa maneira, o autor retoma o debate de outras obras ao abordar a situação histórica e abrir caminho para o futuro a partir do conhecimento de nossa realidade. Sugere como condição para libertar-se do subdesenvolvimento que se escape da obsessão de reproduzir o perfil dos países os quais se autodenominam desenvolvidos e que se assuma uma identidade própria. Na crise de civilização atual, somente a confiança em nós mesmos poder-nos-á restituir a esperança de chegar a um bom porto (FURTADO, 1991).

Para Furtado, a economia tem se desprestigiado devido às suas limitações nas análises. Os problemas socioeconômicos estão mais complexos; as mudanças climáticas, a concentração da riqueza, a miséria e a fome não serão resolvidas somente com os recursos dos/as economistas. Não se pode depender somente deles/as para entender a complexidade de nosso tempo, é preciso somar forças com outras áreas do conhecimento, como política, história, sociologia, entre outras. Conforme, Furtado (1991), espera-se em demasia dos/as economistas, e alguns acreditam que são muito importantes mesmo. Mesmo assim, Furtado tinha esperança nos economistas: [...] "que a atual geração de economistas ilumine com ideias novas os difíceis caminhos na busca da superação do subdesenvolvimento" (1992, p. 54).

\section{Considerações finais}

O atual quadro para os cursos de Economia no Brasil apresenta certa estabilidade, também em relação ao número de economistas formados/as. Embora os cursos com formação afins tenham apresentado crescimento, o número de cursos de Economia passou por drásticas reduções em suas demandas, nas décadas de 1980 e 1990, com o fechamento de muitos em razão da queda de matrículas.

Os/as economistas têm ocupado cada vez mais espaços na mídia. Isso demonstra interesse social em saber a opinião desses/as profissionais. No entanto, esse interesse não tem refletido no aumento pela procura dos cursos de Economia. Ainda é preciso superar a forte tendência à formação "ortodoxa" por uma visão mais ampla, com novas perspectivas da 
fronteira teórica, mais pluralista e interdisciplinar. A formação deve pautar-se em um profissional com maior flexibilidade, na abertura teórica e na tolerância ideológica.

Dada a complexidade das transformações sociais, econômicas e ambientais, o/a economista não pode estar isolado das contribuições das demais áreas do conhecimento. Deve ser capaz de recepcionar e aplicar informações obtidas por modelos que escapam de sua área de conhecimento para encontrar saídas compatíveis com a realidade. O/a economista precisa se relacionar com as demais áreas do conhecimento e pensar como operacionalizará o volume de informações geradas para melhorar o processo de decisão da sociedade, em prol de uma sociedade menos desigual, mais justa e sustentável.

Por isso, se têm um longo caminho a ser trilhado, na formação de economistas, tanto nos aspectos teóricos quanto nos metodológicos. O predomínio, ainda é fazer os/as estudantes aprender as teorias mais aceitas, principalmente as importadas de países desenvolvidos, sem a devida contextualização. Contudo, essas teorias estão distantes de nossa realidade, e essa era a preocupação principal de Celso Furtado. Sendo assim, para transformar a realidade, é preciso formar profissionais comprometidos/as com os problemas e as causas nacionais.

\section{Referências}

ASSIS, J. C.; DORIA, F. O universo neoliberal em desencanto. Rio de Janeiro: Civilização Brasileira, 2011.

ANGE. ASSOCIAÇÃO NACIONAL DOS CURSOS DE GRADUAÇÃO EM CIÊNCIAS ECONÔMICAS (ANGE). Cadernos ANGE: Diretrizes Curriculares Nacionais dos Cursos de Ciências Econômicas - Orientação Acadêmica 2010. [S.1.]: ANGE, 2010. Disponível em: http://www.ange.org.br/site/wp-

content/uploads/2016/02/Cadernos_ANGE_2010_diretrizes.pdf. Acesso em: 23 out. 2020.

BRASIL. Decreto $\mathrm{n}^{\circ} 17.329$, de 28 de maio de 1926. Aprova o regulamento para os estabelecimentos de ensino technico commercial reconhecidos officialmente pelo Governo Federal. Diário Oficial da União. Rio de Janeiro, DF, 10 nov. 1926. Seção 1, p. 20261. Disponível em: https://www2.camara.leg.br/legin/fed/decret/1920-1929/decreto-17329-28maio-1926-514068-republicacao-88142-pe.html. Acesso em: 23 fev. 2019.

BRASIL. Instituto Nacional de Estudos e Pesquisas Educacionais Anísio Teixeira - INEP. Censo da Educação Superior 2018. Brasília, DF: INEP, 2019. Disponível em: http://download.inep.gov.br/educacao_superior/censo_superior/documentos/2019/censo_da_e ducacao_superior_2018-notas_estatisticas.pdf. Acesso em: 30 set. 2020.

BRASIL. Lei $\mathrm{n}^{\circ} 1.411$, de 13 de agosto de 1951. Dispõe sobre a profissão de Economista. Diário Oficial da União. Brasília, DF, 18 ago. 1951. Seção 1, p. 12201. Disponível em: 
https://www2.camara.leg.br/legin/fed/lei/1950-1959/lei-1411-13-agosto-1951-361899publicacaooriginal-1-pl.html. Acesso em: 23 fev. 2020.

BRASIL. Ministério da Educação. Resolução n ${ }^{\circ}$ 02, de 18 de junho de 2007. Dispõe sobre carga horária mínima e procedimentos relativos à integralização e duração dos cursos de graduação, bacharelados. Diário Oficial da União. Brasília, DF, 19 jun. 2007a. Seção I, p. 6. Disponível em: http://portal.mec.gov.br/cne/arquivos/pdf/2007/rces002_07.pdf. Acesso em: 23 fev. 2019.

BRASIL. Ministério da Educação. Resolução $n^{0}$ 04, de 13/07/2007. Institui as Diretrizes Curriculares Nacionais do Curso de Graduação em Ciências Econômicas, bacharelado, e dá outras providências. Diário Oficial da União. Brasília, DF, 14 jul. 2007b. Disponível em: http://portal.mec.gov.br/cne/arquivos/pdf/2007/rces004_07.pdf. Acesso em: 23 set. 2020.

BRESSER PEREIRA, L. C. A teoria econômica e os países subdesenvolvidos. Revista de Administração de Empresas, São Paulo, v. 7, n. 24, jul./set. 1967. Disponível em: http://dx.doi.org/10.1590/S0034-75901967000300001. Acesso em: 23 out. 2020.

CASTRO, N. J. O processo de profissionalização do economista no Brasil: Texto de Debate $\mathrm{n}^{\circ}$ 15. Rio de Janeiro: UFRJ/FEA, 1991.

FANAYA, G. Formação e Mercado de Trabalho do Economista. In: Encontro dos Cursos de Ciências Econômicas do RS, 30, 2007, Cruz Alta. Anais... Cruz Alta, RS: Corecon, 2007. Disponível em: http://www.coreconrs.org.br/palestras/gf.ppt. Acesso em: 07 out. 2020.

FURTADO, C. A formação do economista em país subdesenvolvido. Rio de Janeiro: Faculdade de Ciências Econômicas da Universidade do Estado do Rio de Janeiro, 1961. Disponível em: http://www.centrocelsofurtado.org.br/arquivos/image/201108311213180.A_formacao_do_eco nomista_em_pais_subesenvolvido.pdf. Acesso em: 23 set. 2020.

FURTADO, C. A Pré-revolução brasileira. Rio de Janeiro: Editora Fundo de Cultura, 1962.

FURTADO, C. Dialética do desenvolvimento. Rio de Janeiro: Ed. Fundo de Cultura, 1964.

FURTADO, C. O mito do desenvolvimento econômico. Rio de Janeiro: Paz e Terra, 1974.

FURTADO, C. Os novos desafios. Brasília: Edição 96, 1991. Disponível em: http://www.eco21.com.br/textos/textos.asp?ID=950. Acesso em: 01 nov. 2020.

FURTADO, C. Brasil: a construção interrompida. Rio de Janeiro: Paz e Terra, 1992.

PINTO, H. E. M.; OLIVEIRA, M. E. Recado aos jovens futuros economistas. Brasília: COFECON, 2010. Disponível em: https://www.oeconomista.com.br/recado-aos-jovensfuturos-economistas-e-aos-que-desejam-estudar-economia-por-hugo-meza-pinto-e-marcuseduardo-de-oliveira/. Acesso em: 31 out. 2020.

POLANYI, K. A grande transformação. Rio de Janeiro: Campus, 1980.

SANSON, J. R.; NICOLAU, J. A. Do ensino de técnicas comerciais ao ensino de Economia em Santa Catarina. Análise - Revista de Administração da PUCRS, [S.1.], v. 17, n. 2, p. 297 312, jan. 2007. Disponível em: 
https://www.academia.edu/29690511/Do_ensino_de_t\%C3\%A9cnicas_comerciais_ao_ensino _de_Economia_em_Santa_Catarina. Acesso em: 22 out. 2020.

SEN, A. K. Sobre ética e economia. São Paulo: Companhia das Letras, 1999.

SIMONSEN, M. H. O ensino de economia em nível de pós-graduação no Brasil. Revista Brasileira de Economia, Rio de Janeiro, v. 20, n. 4, p. 19-30, 1966. Disponível em: http://bibliotecadigital.fgv.br/ojs/index.php/rbe/article/viewFile/1769/2785. Acesso em: 10 out. 2020. 